\title{
Insecticide resistance mechanisms with novel 'kdr' type gene mutations in the tropical bed bug Cimex hemipterus
}

Ranindra Punchihewa, W. A. Priyanka P. de Silva, Thilini C. Weeraratne and S. H. P. Parakrama Karunaratne*

\begin{abstract}
Background: The tropical bed bug, Cimex hemipterus, is a serious indoor public health pest in tropical regions causing intense physical discomfort and mental distress to humans. At present, the application of insecticides is the major control strategy. The present study was designed to evaluate the development of resistance and resistance mechanisms in Cimex hemipterus from Kandy district, Sri Lanka.

Methods: The resistance status of the collected bed bugs was determined against the discriminative dosages of DDT, malathion, propoxur, deltamethrin and permethrin by conducting bioassays according to World Health Organization guidelines. Activities of insecticide metabolizing enzymes, i.e. esterases, glutathione S-transferases (GST) and monooxygenases, and the insensitivity of organophosphate/carbamate target site acetylcholinesterase (AChE), were evaluated by biochemical assays. Regions of the gene of the pyrethroid/DDT target site, the voltage-gated sodium channel regulatory protein (VGSC), were sequenced for possible $k d r$ mutations.

Results: Survival percentages of bed bug population were 71, 68 and 51\% for DDT, malathion and propoxur respectively. $\mathrm{KT}_{50}$ and $\mathrm{KT}_{90}$ values, calculated using log-probit mortality curves for deltamethrin were 62.55 and $123.96 \mathrm{~h}$, respectively. These values were much higher for permethrin where $\mathrm{K} \mathrm{T}_{50}$ was $201.10 \mathrm{~h}$ and the $\mathrm{KT}_{90}$ was beyond the detectable range. Results were compared with previous values reported for the same population in 2002. Resistance to propoxur has increased significantly from 11 to $51 \%$ with about a 20 -fold increase in the number of individuals with elevated esterase mechanism. No significant change has occurred in malathion and DDT resistance, in GST and monooxygenase activities, and in AChE sensitivity for the past 14 years. Six kdr associated mutations (Y/L995H, V1010L, 11011F, L1014F, V1016E, L1017F/S) and a non-kdr associated mutation (A1007S mutation) were found from the a-region of the VGSC gene. Out of the kdr type mutations, only L1014F has been reported previously form C. hemipterus while the others have been reported from other insects.
\end{abstract}

Conclusions: The bed bug population has developed high resistance to propoxur with increased esterase activities. $\mathrm{KT}_{50}$ for deltamethrin and permethrin has increased 125- and 20-fold, respectively, over the period 2002 to 2016 . To the authors' knowledge, this is the first time that the possible involvement of a kdr type mutation in developing pyrethroid resistance in C. hemipterus has been shown in Sri Lanka.

Keywords: Cimex hemipterus, Insecticide resistance, $k d r$ type mutations, Resistance mechanisms, Tropical bed bug

*Correspondence: shppkaru@yahoo.com; shppk@pdn.ac.lk

Department of Zoology, Faculty of Science, University of Peradeniya,

Peradeniya 20400, Sri Lanka 


\section{Background}

Bed bugs have become a serious indoor public health pest around the world causing intense physical discomfort and mental distress to humans. In recent years, bed bugs have undergone a major resurgence in the number of infestations in the world [1]. Insecticide resistance is probably the key initiator of the bed bug resurgence, and resistant bed bugs have been disseminated worldwide through increased international travel. The tropical bed bug, Cimex hemipterus, is mainly confined to tropical regions and the common bed bug, C. lectularius, is found in temperate climates. However, both these species may appear beyond their normal ranges and inter-species mating may occur under both laboratory and field conditions, even occasionally producing a species hybrid $[2,3]$.

Cimex spp. are obligatory blood-feeders with the potential to vector pathogens. The most common clinical consequences arising from bed bug bites are direct cutaneous reactions [1]. Although their involvement in transmitting various disease agents such as bacteria (including Rickettsia), viruses, protozoans and nematodes were suspected in early literature, at present there is no evidence to suggest that bed bugs are involved in transmitting pathogens $[4,5]$. Recent studies have reported that bed bugs are potential vectors of Trypanosoma cruzi [6, 7]. However, the physical stress, sleep deprivation and the mental health consequences arising from infestations have been reported to be serious [8]. Bed bug infestations have closed down hostels, hotels and even hospitals [1]. In the poultry industry, heavy infestations in poultry sheds have resulted in anemia and decreased egg production in chicken [9].

Non-chemical control mainly involves disposal of infested items, vacuuming and heat treatments $[10,11]$. A variety of chemical formulations are available as powder dusts, fumigants and liquids against bed bugs. One major issue is the ineffectiveness of the insecticides labeled for bed bug control in the market and the main reason everywhere has been the failure of government insecticide registration authorities in evaluating the efficacy of new products based on insecticide resistance and resistance mechanisms of bed bug populations [12-14]. Overuse and misuse of insecticides for bed bug control has also led to increased selection pressure and thus to the rapid development of insecticide resistance [15]. Today, the vast majority of insecticides in use worldwide against bed bugs are pyrethroids. Resistance development against organochlorines, organophosphates (OPs), carbamates and pyrethroids has been documented for both species $[1,16,17]$.

Although the mechanisms of resistance have been extensively studied in C. lectularius, only a few studies have been conducted with $C$. hemipterus. In insects, the increased metabolism of insecticides (metabolic resistance) through elevated enzyme activity and/or decreased target site sensitivity are the two major mechanisms of insecticide resistance. Metabolic resistance involves quantitative (through gene amplification, increased transcription and increased mRNA stability) and/or qualitative (through gene mutation) changes of insecticide metabolizing enzymes, i.e. esterases, glutathione S-transferases (GSTs) and monooxygenases [18, 19]. Point mutations in the voltage-gated sodium channel gene (VGSC) are responsible for the decrease sensitivity of the target sites for pyrethroids and DDT causing "knockdown resistance" $(k d r)$. Two $k d r$ type mutations have been previously reported from C. lectularius (V419L and L925I) and four have been reported from C. hemipterus (L899V, M918I, D953G and L1014F) [20]. Insecticide resistance and the underlying resistance mechanisms in the bed bug $C$. hemipterus collected from three districts of Sri Lanka were investigated in 2002 [21]. Here we report the development of increased resistance to propoxur with enhanced activity of esterases, and unusually high resistance to pyrethroids in one of these populations with six $k d r$ type mutations, which have not (to the authors' knowledge) been previously reported in C. hemipterus.

\section{Methods \\ Bed bug collection}

Bed bugs were collected from the previously described study sites [21] of Kandy district $\left(7^{\circ} 15^{\prime} \mathrm{N}, 80^{\circ} 35^{\prime} \mathrm{E}\right.$; elevation 270-1060 m above sea level) in Sri Lanka during the period March to October of 2016. Samples were collected from 6 study sites and the maximum distance between these study sites was $2 \mathrm{~km}$. Bed bugs were collected from crevices and cracks in the furniture and walls, and from bed mattresses using paintbrushes and forceps. Live bugs were brought to the laboratory and identified under a stereomicroscope. The identification of bed bugs was based on the key of Furman \& Catts [22]. Blood-fed bed bugs were used for insecticide bioassays. Unfed bed bugs and the blood-fed bed bugs which were allowed to digest the blood meals, were snap frozen and stored at $-20{ }^{\circ} \mathrm{C}$ for biochemical and molecular assays.

\section{Chemicals and equipment}

Chemicals were purchased from Sigma Chemicals UK (Haverhill, UK) unless otherwise stated. Permethrin (lot no. SZBD142XV), DDT (lot no. 360129B) and malathion (lot no. 352-138A) (97-99\% pure) were a gift from the Liverpool School of Tropical Medicine, UK. Propoxur (lot no. SZBD302XV) was purchased from Bayer (Leverkusen, Germany). UVmaxELx $800^{\mathrm{TM}}$ microtiter plate reader was from Molecular Devices, Bio-Tek, Winooski, 
VT, USA. The protein assay kit was from Bio-Rad (Dalkeith, UK).

\section{Preparation of insecticide papers}

Insecticide impregnated papers were made according to the standard World Health Organization (WHO) insecticide impregnated paper method for the discriminating dosages specified by the WHO [23]. Only the discriminating dosage for DDT (2\%) was available for C. hemipterus so those described for the common bed bug $(C$. lectularius) were used for malathion (5\%), propoxur $(0.8 \%)$, permethrin $(0.25 \%)$ and deltamethrin $(0.025 \%)$ [24]. Required concentrations were prepared by mixing the technical grade insecticides with a carrier; olive oil was used as the carrier for propoxur, malathion and DDT while Dow Corning 556 silicon fluid was used for permethrin and deltamethrin. Rectangles of Whatman No. 1 filter papers $(12 \times 15 \mathrm{~cm})$ were impregnated with $0.7 \mathrm{ml}$ of insecticide/carrier solution. An equal volume of acetone $(0.7 \mathrm{ml})$ was used to ensure an even distribution of this solution on the paper. Papers were left at room temperature until the acetone had evaporated. They were then foil-wrapped and stored at $-20^{\circ} \mathrm{C}$.

\section{Bioassays}

Adult bed bugs from the selected study sites were pooled together and subjected to insecticide bioassays via tarsal contact to insecticide impregnated papers using WHO mosquito bioassay kits [23]. Bed bugs were exposed to the insecticides as recommended by the WHO, i.e. 24 $\mathrm{h}$ for DDT and propoxur, $16 \mathrm{~h}$ for malathion, and continuous exposure for deltamethrin and permethrin. The insecticide chambers were fully covered using the insecticide impregnated papers and 10-15 bugs were exposed for one trial. After the fixed time periods, mortalities were recorded for DDT, malathion and propoxur while knock-down rates were recorded for deltamethrin and permethrin [24]. At least five replicates were carried out for each insecticide. Control insects were exposed to papers impregnated with carrier oil alone. Results were used only if the mortality/knockdown rate in the controls was $<20 \%$. Control mortalities were adjusted for using Abbott's formula [25].

\section{Biochemical assays}

All the biochemical experiments were carried out according to the procedures outlined by the WHO [26] with slight modifications. Two hundred twenty-five randomly selected $C$. hemipterus adults were subjected to total protein, esterase, GST, monooxygenase and acetylcholinesterase assays in three replicates. Individual bed bugs were homogenized in $300 \mu \mathrm{l}$ of ice-cold distilled water. An aliquot of $100 \mu \mathrm{l}$ was taken for the acetylcholinesterase assay and the rest was centrifuged at $13,000 \times \mathrm{rpm}$ for $2 \mathrm{~min}$. The supernatant was used for esterase, GST, monooxygenase and protein assays [21].

\section{Detection of $k d r$ mutations}

DNA was extracted from 11 individuals of C. hemipterus using LIVAK extraction buffer [27]. Primers that had been designed to amplify the exon region between domain II S4 loop and domain II S5 of the gene code for VGSC regulatory protein to detect resistance-conferring mutations were used [28]. BBParaF1 (5'-AAC CTG GAT ATA CAT GCC TTC AAG G-3') and BBParaR1 (5'-TGA TGG AGA TTT TGC CAC TGA TG-3') were used to amplify fragment I and BBParaF3 (5'-CGA ATT GAA GCT GCC ATG AAG TTG-3') and BBParaR3 (5'-TGC CTA TTC TGT CGA AAG CCT CAG-3') were used to amplify fragment III. The PCR reaction contained $2 \mu \mathrm{l}$ of each primer $(10 \mathrm{mmol}), 14 \mu \mathrm{l}$ of $2 \times \mathrm{GoTaq}^{\circledR}$ Green Master Mix, $5 \mu \mathrm{l}$ of DNA template and $4 \mu \mathrm{l}$ of NucleaseFree Water (Promega, Madison, WI, USA). The mixture was amplified in a thermocycler for 30 cycles $\left(95^{\circ} \mathrm{C}\right.$ for $1 \mathrm{~min}$ followed by 30 cycles of $95{ }^{\circ} \mathrm{C}$ for $30 \mathrm{~s}, 55^{\circ} \mathrm{C}$ for $45 \mathrm{~s}$ and $72{ }^{\circ} \mathrm{C}$ for $60 \mathrm{~s}$, and a final extension step at 72 ${ }^{\circ} \mathrm{C}$ for $7 \mathrm{~min}$ ). An annealing temperature of $55^{\circ} \mathrm{C}$ for 45 $\mathrm{s}$ was used to amplify fragment 1 and that of $58^{\circ} \mathrm{C}$ for 45 $\mathrm{s}$ was used to amplify fragment 3 . Products were viewed on an ethidium bromide stained $1 \%$ agarose gel. DNA sequencing was carried out using an automatic DNA sequencer (Series 3500, Applied Biosystems, Waltham, MA, USA) and the sequence was read for possible mutations. The sequences of gene fragments were aligned using ClustalW and compared using BioEdit software version 7.2. The GenBank database (NCBI) was used for blast searches with the VGSC gene of Musca domestica (accession number: AAB47604).

\section{Data analysis}

SigmaPlot v.10 was used to obtain log-probit curves for insecticide concentrations against response knockdown rates (KT). $\mathrm{KT}_{50}$ and $\mathrm{KT}_{90}$ values for each bed bug population were estimated by regression analysis. Significant variations between elevated levels of enzyme activities of 2016 and 2002 bed bug populations and the percentage mortalities were performed using paired $t$-tests (Minitab v.15).

\section{Results}

A total of 738 bed bugs were collected from the study sites and all were identified as $C$. hemipterus, from the ratio of length to width of the pronotum [22]. Percentage survivals resulting from DDT, malathion and propoxur bioassays are given in Table 1. No mortalities occurred in the control bioassay experiments. The bed bug population 
Table 1 Percentage survival of Kandy bed bugs after exposure to discriminating dosages of DDT, malathion and propoxur ( $n>100$ per insecticide). Exposure time for DDT and propoxur was $24 \mathrm{~h}$ whereas that for malathion was $16 \mathrm{~h}$ [24]. Data from the 2002 population [21] are also presented for comparison. Populations were statistically compared using two sample t-tests

\begin{tabular}{|c|c|c|c|c|c|c|}
\hline \multirow[t]{2}{*}{ Insecticide } & \multicolumn{2}{|l|}{2002} & \multicolumn{2}{|l|}{2016} & \multicolumn{2}{|c|}{ Comparison } \\
\hline & $\%$ survival & Status ${ }^{a}$ & $\%$ survival & Status ${ }^{a}$ & $t$-value ${ }^{b}$ & $P$-value \\
\hline DDT (2\%) & 71 & Resistant & 71 & Resistant & 0.132 & 1 \\
\hline Malathion (5\%) & 64 & Resistant & 68 & Resistant & 0.132 & 1 \\
\hline Propoxur (0.8\%) & 11 & Possibly resistant & 51 & Resistant & 4.532 & $0.0062^{*}$ \\
\hline
\end{tabular}

a According to the classification of the WHO (2016): susceptible, >98\% mortality; possibly resistant, 80-98\% mortality; resistant, < 80\% mortality

b Degrees of freedom: 5 for all comparisons

*Significantly different

Table 2 Time (h) taken to knockdown 50\% ( $\mathrm{KT}_{50}$ ) and 90\% ( $\left.\mathrm{KT}_{90}\right)$ of the Kandy Cimex hemipterus population when exposed to discriminating dosages of deltamethrin and permethrin ( $n>100$ per insecticide) [24]. Data from the 2002 population [21] are also presented for comparison

\begin{tabular}{|c|c|c|c|c|}
\hline \multirow[t]{2}{*}{ Insecticide } & \multicolumn{2}{|l|}{2002} & \multicolumn{2}{|l|}{2016} \\
\hline & $\mathrm{KT}_{50}$ & $\mathrm{KT}_{90}$ & $\mathrm{KT}_{50}(95 \% \mathrm{Cl})$ & $\mathrm{KT}_{90}(95 \% \mathrm{Cl})$ \\
\hline Deltamethrin (0.025\%) & 0.5 & 1.0 & $62.55(52.08-76.80)$ & 123.96 (96.57-186.89) \\
\hline Permethrin $(0.25 \%)$ & 10 & 24 & $201.10(100.96-1653.00)$ & a \\
\hline
\end{tabular}

a Beyond the detectable level (see the text for details)

Abbreviation: $\mathrm{Cl}, 95 \%$ confidence interval

was resistant to all three insecticides tested. Comparatively, the highest level of resistance was shown to DDT while the lowest resistance was to propoxur. Resistance levels of the bed bug population, collected from the same area in 2002 to these three insecticides [21], are also present in Table 1 for comparison. Interestingly, resistance to malathion and DDT has not been changed for the last 14 years whereas propoxur resistance has increased from $11 \%$ to $51 \%$. For permethrin, knock-down rates were much higher than that for the deltamethrin and a complete log-probit mortality curve could not be obtained as only about $50 \%$ of bed bugs were knocked down even after a one week of exposure to the discriminating dosage of permethrin. Pyrethroid bioassay results are presented in the Table 2 with the data of 2002 for comparison. No knock-downs were detected in the controls during the experimental period.

Results of the biochemical assays, conducted to assess the activity levels of insecticide detoxifying enzymes GSTs, carboxylesterases and monooxygenases in the bed bug C. Hemipterus population are shown in Figs. 1, 2, 3. Activity levels of these enzymes in the $C$. hemipterus population in 2002 are also presented to show the change over the years.

GST specific activity above $0.40 \mu \mathrm{mol} \mathrm{min}^{-1} \mathrm{mg}^{-1}$ of protein was previously considered as a high activity which could contribute to metabolic resistance [21]. About $50 \%$ of the 2002 population and $32 \%$ of the

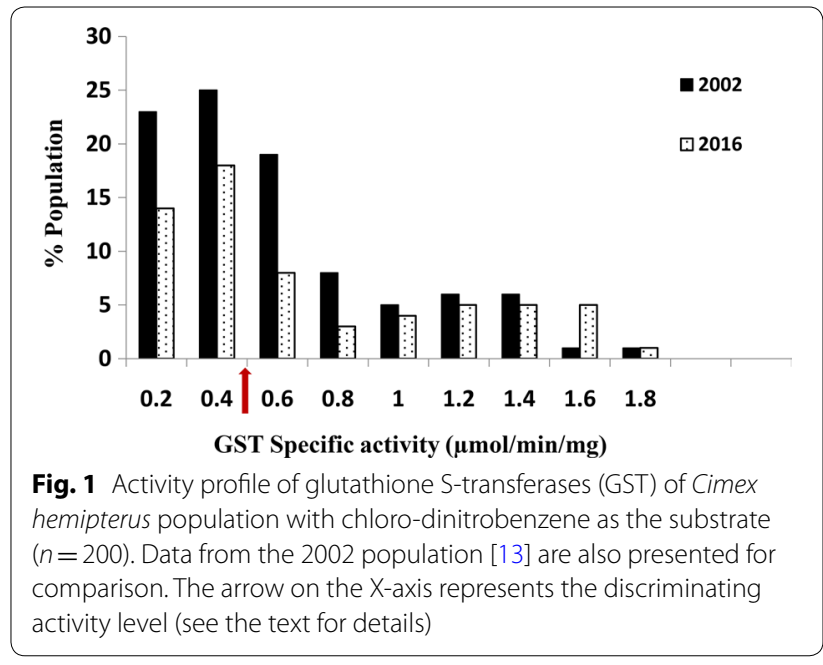

2016 population had relatively high GST activities, but the difference was not significant $\left(t_{(9)}=0.67, P=0.80\right)$. The discriminating esterase activity was $0.12 \mu \mathrm{mol}$ $\mathrm{min}^{-1} \mathrm{mg}^{-1}$ of protein and only about $4 \%$ of the population had an esterase activity above this level for the 2002 population. In 2016, 83\% of the population had an esterase activity more than the discriminating levels showing a significant increase in esterase activity $\left(t_{(8)}=1.88, P=0.04\right)$. Monooxygenases in the bed bug populations were indirectly quantified by measuring 


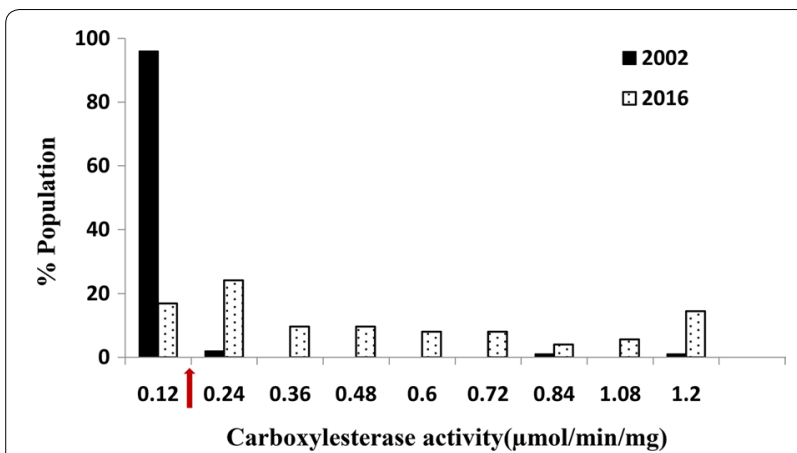

Fig. 2 Activity profile of carboxylesterases of Cimex hemipterus population with $\rho$-nitrophenyl acetate as the substrate $(n=200)$. Data from the 2002 population [13] are also presented for comparison. The arrow on the $\mathrm{X}$-axis represents the discriminating activity level (see the text for details)

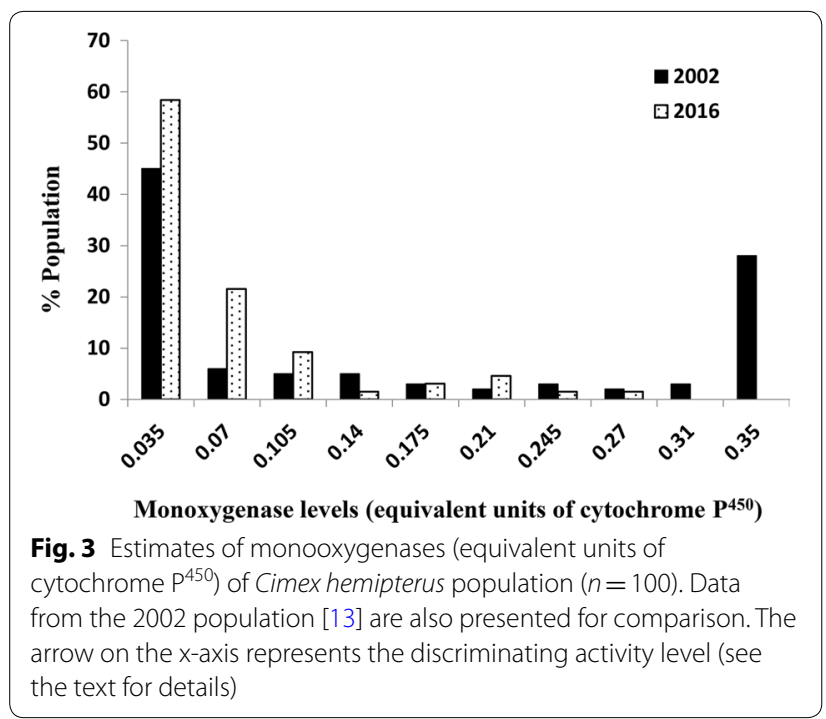

bound haem [29]. Quantities below 0.35 equivalent units of cytochrome $\mathrm{P}^{450}$ have been reported from mosquitoes and ticks susceptible to this mechanism [30]. Monooxygenase activities of the 2016 population also fall within the susceptibility levels (Fig. 3) and the overall monooxygenase profiles between the two populations were not significantly different $\left(t_{(9)}=0.91\right.$, $P=0.19$ ).

The percentage remaining activities of OP and carbamate target site AChE of the $C$. hemipterus population is also presented with relevant data from the previous work (Fig. 4). According to WHO guidelines [26], results of this assay can be used to categorize the population into percentages of susceptible homozygous (SS, $<30 \%$ remaining activity), heterozygous (RS, $30-70 \%$ remaining activity) and resistant homozygous (RR,

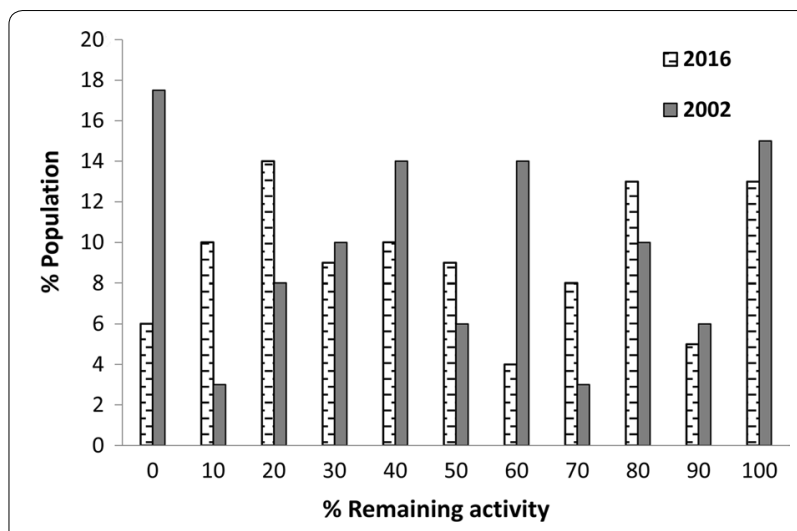

Fig. 4 Percentage remaining activity of Cimex hemipterus acetylcholinesterases (AChEs) after inhibition with propoxur. Values were calculated as a fraction of the uninhibited activity of the same bed bug ( $n=200)$. Data from the 2002 population [13] are also presented for comparison

$>70 \%$ remaining activity) of altered or insensitive target site activity of AChE. Results showed that $30 \%$ of the bed bug population is susceptible homozygous, $32 \%$ of the population is heterozygous while $38 \%$ of the population is resistant heterozygous for the altered AChE mechanism in the present population of $C$. hemipterus. Respective values for the 2002 population were $25 \%$, $45 \%$ and $30 \%\left(t_{(10)}=0.17, P=0.43\right)$.

DNA sequencing of fragment I and fragment III of the $\alpha$-region of the $V G S C$ gene revealed the presence of mutations at Y/L995H, A1007S, V1010L, I1011F, L1014F, V1016E and L1017F/S in C. hemipterus (Fig. 5). $k d r$ mutations L1014F and L1017S were found in 10 individuals (90.9\%) and another six mutations were present in a single individual (9.1\%). Out of these, A1007S mutation has been identified as having no association with the pyrethroid or DDT resistance [31]. All the other mutations have been identified as mutations of the VGSC gene facilitating $k d r$ type insecticide resistance.

\section{Discussion}

Early practices of bed bug control in Sri Lanka included applying boiling water and herbal extracts to small holes/ crevices of the home furniture on which people sit or sleep. Insecticide treatment subsequently replaced these traditional measures. DDT was heavily used in insect control programmes until its cessation due to resistance development and environmental concerns in the mid1970s in Sri Lanka. OPs and carbamates replaced DDT and pyrethroids were introduced in 1994. Pyrethroids became the major synthetic insecticide group used against the insect pests of both agricultural and health sectors, mainly due to their low mammalian toxicity and high efficacy. Bed bugs are also often controlled as a 


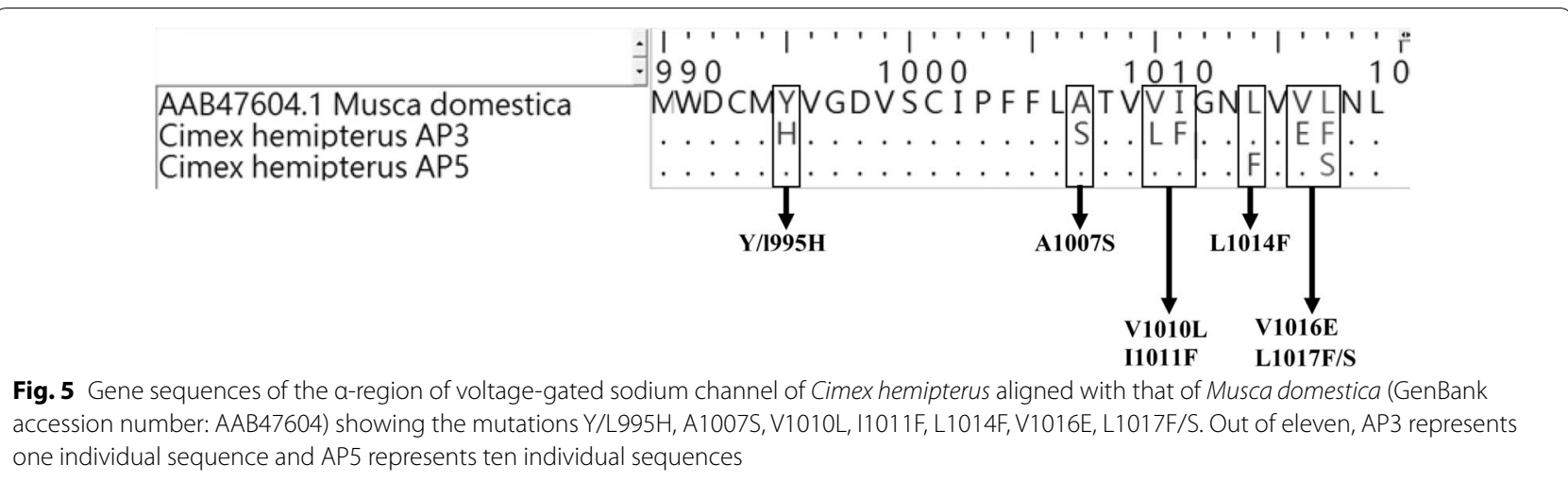

side-effect of mosquito control activities [32]. The development of DDT resistance in bed bugs as a response to anti-malaria indoor house-spraying campaigns [17, 32, 33] and pyrethroid resistance due to insecticide treated bed nets [34, 35] have been documented. DDT, Ops chlorpyrifos and dichlorvos, and the carbamate propoxur were the mainly used insecticides for bed bug control by householders in Sri Lanka until the introduction of pyrethroid formulations.

The present bioassay results show that the Kandy bed bug population has developed a very high level of pyrethroid resistance as a result of the increased use of pyrethroids. Resistance to pyrethroids has increased significantly over the period 2002 to 2016 and the time taken to kill $50 \%$ of the population has been increased 2.7 -fold for deltamethrin and 15.1-fold for permethrin. $k d r$ type mutations that could bring about pyrethroid resistance were not tested during the 2002 bed bug study. However, it is evident that several different mutations at the VGSC gene are responsible for the development of a high level of resistance to pyrethroids, mainly because the observed changes in metabolic enzyme activity levels are unlikely to provide such a resistance difference for pyrethroids although the increased esterase activity might be contributory to some extent. The contribution of other mechanisms, such as cuticular thickness, has been reported for pyrethroid resistance in C. lectularius [36].

Although DDT shares the same VGSC target site with pyrethroids, mutations occurring in the VGSC gene are unlikely to cause any DDT resistance, since the same magnitude of DDT resistance was shown in both 2002 and 2016 bed bug populations. Interestingly, the activity profiles of GSTs, which are mainly responsible for organochlorine metabolism, are similar in both populations. The persistence of a high level of DDT resistance in Sri Lankan insect populations long after its discontinuation has become a unique feature in almost all the insect populations in Sri Lanka [37-41]. This may be due to the fact that the mechanisms which were originally selected against DDT have later provided resistance to subsequently used insecticides or the mechanisms selected for the subsequently used insecticides provide cross-resistance to DDT.

Increased carbamate resistance can be correlated with increased esterase activities. However, malathion resistance, which had been developed through malathion carboxylesterase activity as a result of heavy malathion usage in anti-malarial activities in the past [21], remains unchanged. Insensitivity of the OP and carbamate target site $\mathrm{AChE}$ has not altered largely, and the monooxygenase levels have slightly decreased over the years.

The $k d r$ type mutations of bed bug populations have been previously reported for C. Lectularius (V419L and L925I) and C. hemipterus (L899V, M918I, D953G and L1014F) $[19,20]$. $K d r$ type mutations except for L1014F discovered in the VGSC gene during the present study are, to our knowledge, new records for the bed bug $C$. hemipterus. Thus, the six reported bed bug " $k d r$ " mutations; Y/L995H, A1007S, V1010L, I1011F, V1016E and L1017F/S are new records for C. hemipterus.

From these six mutations, except A1007S mutations, all the other mutations have been previously reported as $k d r$ type mutations causing pyrethroid and DDT resistance in Anopheles and Aedes mosquitoes. The Y/L995H mutation has been reported from Iranian Anopheles culicifacies $[42,43]$. V1010L $k d r$ mutation has been reported from 13 species of Anopheles mosquitoes from African, Asian and also from American continents [44, 45]. Even though the I1011V/M and V1016G are the commonly $k d r$ type mutations [46, 47], Kandy bed bug population loci had slightly different amino acid substitutions as I1011F and V1016E. A1007S mutation has been previously reported from An. funestus from northern Cameroon [31], but with no association with $k d r$. The mutation I1017F has been reported from spiders, mites and ticks [48]. The present study reported the $k d r$ mutation L1014F with a 
very high frequency. This mutation has been identified as one of the most common types of mutations present in many pyrethroid resistant insects, including C. hemipterus [20]. Hence, L1014F in Sri Lankan C. hemipterus also might contribute to pyrethroid resistance. However, further studies are needed to confirm and characterize the association between these mutations and the pyrethroid resistance of $C$. hemipterus.

The present study highlights that the bed bugs have developed a high level of resistance to all groups of synthetic insecticides. Resistant bed bugs are easily dispersed from place to place through infested cloths and other goods of humans. Efforts to control bed bugs using insecticides at the University of Peradeniya hostels, where about 5000 students reside, failed. It is important to look for alternative control methods for bed bugs. One such alternative is a properly managed heat treatment, which has been identified as a successful method of bed bug management [49-51]. Bed bugs die at temperatures $\geq 41{ }^{\circ} \mathrm{C}$ and the exposure time required shortens as the temperature increases [51,52]. A study with dichlorvos in resin strips combined with heat and air treatments used in college dormitories has become successful in controlling abed bug population in the USA [53]. Future bed bug control programmes should be based on integrative approaches and future research should also be directed towards designing insecticides with novel target sites.

\section{Conclusions}

The tropical bed bug C. hemipterus has developed a high level of pyrethroid and carbamate resistance through $k d r$ type mutations and elevated esterases, respectively. The use of integrated approaches combining biological, physical and chemical methods should be emphasized in future bed bug control programmes.

\begin{abstract}
Abbreviations
GST: glutathione S-transferase; AChE: acetylcholinesterase; VGSC: voltagegated sodium channel; $k d r$ : knockdown resistance; OPs: organophosphates; WHO: World Health Organization; $\mathrm{KT}_{50}$ : time taken to knockdown $50 \%$ of the population; $\mathrm{KT}_{90}$ : time taken to knockdown $90 \%$ of the population.
\end{abstract}

\section{Acknowledgements}

We thank Mr Nalaka Nugapola and Ms. Janadaree Bandara for their assistance given during the bed bug collections and the laboratory work.

\section{Authors' contributions \\ SHPPK and WAPPdeS conceptualized and designed the work. RP collected data. SHPPK, WAPPdeS, RP and TCW contributed to the analysis of data, discussion and writing the manuscript. All authors read and approved the final manuscript.}

\section{Funding}

This work was supported by the University of Peradeniya, Sri Lanka (Grant no. $\ln R C / R G / 13 / 21$.

\section{Availability of data and materials}

The datasets used and/or analyzed during the present study are available from the corresponding author upon reasonable request.

\section{Ethics approval and consent to participate}

Not applicable.

\section{Consent for publication}

Not applicable.

\section{Competing interests}

The authors declare that they have no competing interests.

Received: 15 December 2018 Accepted: 15 June 2019

Published online: 21 June 2019

\section{References}

1. Doggett SL, Dwyer DE, Penas PF, Russell RC. Bed bugs, clinical relevance and control options. Clin Microbiol Rev. 2012;25:164-92.

2. Gbakima AA, Terry BC, Kanja F, Kortequee S, Dukuley I, Sahr F. High prevalence of bed bugs Cimex hemipterus and Cimex lectularius in camps for internally displaced persons in Freetown, Sierra Leone, a pilot humanitarian investigation. West Afr J Med. 2002;21:268-71.

3. Newberry K. Production of a hybrid between the bed bugs Cimex hemipterus and Cimex lectularius. Med Vet Entomol. 1988;2:297-300.

4. Goddard J. Do bed bugs carry human diseases. A controversy. Pest Control Technol. 2003;31:38-40.

5. Goddard J. Bed bugs, vectors of human disease. Pest Control Technol. 2009;37:44-55.

6. Salazar R, Castillo-Neyra R, Tustin AW, Borrini-Mayorí K, Náquira C, Levy MZ. Bed bugs (Cimex lectularius) as vectors of Trypanosoma cruzi. Am J Trop Med Hyg. 2015;92:331-5.

7. Blakely BN, Hanson SF, Romero A. Survival and transstadial persistence of Trypanosoma cruzi in the bed bug (Hemiptera: Cimicidae). J Med Entomol. 2018;55:742-6.

8. Susser SR, Perron S, Fournier M, Jacques L, Denis G, Tessier F, et al. Mental health effects from urban bed bug infestation of Cimex lectularius $L .:$ a cross-sectional study. BMJ Open. 2012;2:e000838.

9. Cater J, Magee D, Edwards KT. Severe infestation of bed bugs in a poultry breeder house. J Am Vet Med Assoc. 2011;239:919-22.

10. Johnson CG. The ecology of the bed-bug, Cimex lectularius L., in Britain. J Hyg Lond. 1941;41:345-461.

11. Naylor RA, Boase CJ. Practical solutions for treating laundry infested with Cimex lectularius, Hemiptera, Cimicidae. J Econ Entomol. 2010;103:136-9.

12. Potter MF. A bed bug state of mind: emerging issues in bed bug management. Pest Control Technol. 2005;33:82-85, 88, 90, 92-93, 96-97.

13. Potter MF. The history of bed bug management-with lessons from the past. Am Entomol. 2011;57:14-25.

14. Romero A, Potter MF, Potter DA, Haynes KF. Insecticide resistance in the bed bug: a factor in the pest's sudden resurgence? J Med Entomol. 2007:44:175-8.

15. Zhu F, Lavine L, O'Neal S, Lavine M, Foss C, Walsh D. Insecticide resistance and management strategies in urban ecosystems. Insects. 2016;7:2.

16. Kilpinen O, Kristensen M, Jensen KM. Resistance differences between chlorpyrifos and synthetic pyrethroids in Cimex lectularius population from Denmark. Parasitol Res. 2011;109:1461-4.

17. Dang K, Doggett LS, Singham GV, Lee CY. Insecticide resistance and resistance mechanisms in bed bugs, Cimex spp. (Hemiptera: Cimicidae). Parasit Vectors. 2017:10:318.

18. Karunaratne SHPP, de Silva WAPP, Weeraratne TC, Surendran SN. Insecticide resistance in mosquitoes: development, mechanisms and monitoring. Ceylon J Sci. 2018;47:299-309.

19. Yoon KS, Kwon DH, Strycharz JP, Hollingsworth CS, Lee SH, Clark JM. Biochemical and molecular analysis of deltamethrin resistance in the common bed bug (Hemiptera: Cimicidae). J Med Entomol. 2008:45:1092-101.

20. Dang K, Toi CS, Lilly DG, Lee CY, Naylor R, Tawatsin A, et al. Identification of putative kdr mutations in the tropical bed bug, Cimex hemipterus (Hemiptera: Cimicidae). Pest Manag Sci. 2015;71:1015-20. 
21. Karunaratne SHPP, Damayanthi BT, Fareena MHJ, Imbuldeniya V, Hemingway J. Insecticide resistance in the tropical bed bug Cimex hemipterus. Pest Biochem Physiol. 2002;88:102-7.

22. Furman DP, Catts EP. Manual of medical entomology. 4th ed. Cambridge: Cambridge University Press; 1986

23. World Health Organization. Criteria and meaning of tests for determining susceptibility or resistance of insects to insecticides. WHO Technol RepSer. 1963;265:135-8.

24. WHO. Vector resistance to pesticides, 15th report of the WHO expert Committee on vector biology and control. Geneva: World Health Organization; 1991.

25. Matsumara F. Toxicology of insecticides. New York: Plenum Press; 1985.

26. WHO. Test procedures for insecticide resistance monitoring in malaria vector mosquitoes. Geneva: World Health Organization; 2016.

27. Livak KJ. Organization and mapping of a sequence on the Drosophila melanogaster $X$ and $Y$ chromosomes that is transcribed during spermatogenesis. Genetics. 1984;107:611-34.

28. Zhu F, Wigginton J, Romero A, Moore A, Ferguson K, Palli R, et al. Widespread distribution of knockdown resistance mutations in the bed bug, Cimex lectularius, populations in the United States. Arch Insect Biochem Physiol. 2010;73:245-57.

29. Brogdon WG, MCAllister JC, Vulule J. Heme peroxidase activity measured in single mosquitoes identifies individual expression of elevated oxidases for insecticide resistance. J Am Mosq Control Assoc. 1997;13:233-5.

30. Bandara KMUJ, Karunaratne SHPP. Mechanisms of acaricide resistance in the cattle tick Rhipicephalus (Boophilus) microplus in Sri Lanka. Pestic Biochem Physiol. 2017;139:68-72.

31. Menze BD, Riveron JM, Ibrahim SS, Irving H, Antonio-Nkondjio C, AwonoAmbene $\mathrm{PH}$, et al. Multiple insecticide resistance in the malaria vector Anopheles funestus from Northern Cameroon is mediated by metabolic resistance alongside potential target site insensitivity mutations. PLoS ONE. 2016;11:e0163261.

32. Temu EA, Minjas JN, Shiff CJ, Majala A. Bed bug control by permethrinimpregnated bed nets in Tanzania. Med Vet Entomol. 1999;13:457-9.

33. Busvine JR. Insecticide resistance in bed-bugs. Bull WHO.

1958;19:1041-52

34. Lofgren CS, Keller JC, Burden GS. Resistance tests with the bed bug and evaluation of insecticides for its control. J Econ Entomol. 1958;51:241-4.

35. Myamba J, Maxwell CA, Asidi A, Curtis CF. Pyrethroid resistance in bed bugs, Cimex hemipterus, associated with use of treated bed nets. Med Vet Entomol. 2002;16:448-51.

36. Lilly DG, Latham SL, Webb CE, Doggett SL. Cuticle thickening in a pyrethroid-resistant strain of the common bed bug, Cimex lectularius $\mathrm{L}$. (Hemiptera, Cimicidae). PLoS ONE. 2016;11:e0153302.

37. Karunaratne SHPP. Insecticide cross-resistance spectra and underlying resistance mechanisms of Sri Lankan anopheline vectors of malaria. Southeast Asian J Trop Med Public Health. 1999:30:460-9.

38. Perera MDB, Hemingway J, Karunaratne SHPP. Multiple insecticide resistance mechanisms involving metabolic changes and insensitive target sites selected in anopheline vectors of malaria. Malar J. 2008;7:168-77.

39. Karunaratne SHPP, Weeraratne TC, Perera MD, Surendran SN. Insecticide resistance and efficacy of space spraying and larviciding in the control of dengue vectors Aedes aegypti and Aedes albopictus in Sri Lanka. Pestic Biochem Physiol. 2013;107:98-105.

40. Damayanthi BT, Karunaratne SHPP. Biochemical characterization of insecticide resistance in vegetable insect pests and predatory ladybird beetles. J Nat Sci Found Sri Lanka. 2005:33:115-22.

41. Karunaratne SHPP, Hemingway J. Insecticide resistance spectra and underlying resistance mechanisms in populations of Japanese encephalitis vector mosquitoes, Culex tritaeniorhynchus and C. gelidus, in Sri Lanka. Med Vet Entomol. 2000;14:430-6.

42. Djadid ND, Forouzesh F, Karimi M, Raeisi A, Hassan-Zehi A, Zakeri S. Monitoring pyrethroid insecticide resistance in major malaria vector Anopheles culicifacies, comparison of molecular tools and conventional susceptibility test. Iran Biomed J. 2007;11:169-76.

43. Singh OP, Bali P, Hemingway J, Subbarao SK, Dash AP, Adak T. PCR-based methods for the detection of L1014 kdr mutation in Anopheles culicifacies sensu lato. Malar J. 2009:8:154

44. Singh OP, Dykes CL, Das MK, Pradhan S, Bhatt RM, Agrawal OP, et al. Presence of two alternative kdr-like mutations, L1014F and L1014S, and a novel mutation, $\mathrm{V} 1010 \mathrm{~L}$, in the voltage gated Na+ channel of Anopheles culicifacies from Orissa, India. Malar J. 2010;9:146.

45. Silva APB, Santos JMM, Martins AJ. Mutations in the voltage-gated sodium channel gene of anophelines and their association with resistance to pyrethroids-a review. Parasit Vectors. 2014;7:450.

46. Kawada H, Higa Y, Komagata O, Kasai S, Tomita T, Yen NT, et al. Widespread distribution of a newly found point mutation in voltage-gated sodium channel in pyrethroid-resistant Aedes aegypti populations in Vietnam. PLoS Negl Trop Dis. 2009;3:e527.

47. Kawada H, Oo SZM, Thaung S, Kawashima E, Maung YNM, Thu HM, et al. Co-occurrence of point mutations in the voltage-gated sodium channel of pyrethroid-resistant Aedes aegypti populations in Myanmar. PLoS Negl Trop Dis. 2014;8:e3032.

48. Ilias A, Vontas J, Tsagkarakou A. Global distribution and origin of target site insecticide resistance mutations in Tetranychusurticae. Insect Biochem Mol Boil. 2014;48:17-28.

49. Kells SA. Nonchemical control of bed bugs. Am Entomol. 2006;52:109-10.

50. Pinto J, Lynd A, Vicente JL, Santolamazza F, Randle NP, Gentile G, et al. Multiple origins of knockdown resistance mutations in the Afrotropical mosquito vector Anopheles gambiae. PLOS ONE. 2007;2:e1243.

51. Pereira RM, Koehler PG, Pfiester M, Walker W. Lethal effects of heat and use of localized heat treatment for control of bed bug infestations. J Econ Entomol. 2009;102:1182-8.

52. Usinger RL. Monograph of cimicidae, hemiptera, heteroptera. Maryland: Entomological Society of America; 1966.

53. Lenhert S, Nafday OA, Lowry TW. U.S. Patent Application No. 14/818. 2015 p. 501.

\section{Publisher's Note}

Springer Nature remains neutral with regard to jurisdictional claims in published maps and institutional affiliations.
Ready to submit your research? Choose BMC and benefit from:

- fast, convenient online submission

- thorough peer review by experienced researchers in your field

- rapid publication on acceptance

- support for research data, including large and complex data types

- gold Open Access which fosters wider collaboration and increased citations

- maximum visibility for your research: over 100M website views per year

At BMC, research is always in progress.

Learn more biomedcentral.com/submissions 